\title{
In Situ Formation of Silver Nanoparticles (Ag-NPs) onto Textile Fibers
}

\author{
German Montes-Hernandez,* Mahaut Di Girolamo, Géraldine Sarret, Sarah Bureau, \\ Alejandro Fernandez-Martinez, Cécile Lelong, and Elise Eymard Vernain
}

Cite This: ACS Omega 2021, 6, 1316-1327

Read Online

ACCESS I

Llll Metrics \& More

Article Recommendations

Supporting Information

ABSTRACT: Silver nanoparticles (Ag-NPs) adhered/inserted on textile fibers have an effective antimicrobial role. However, their release due to low adherence and their fate in the natural settings have been questioned in terms of toxicity level. In order to overcome this recurrent problem of adherence, the in situ formation of Ag-NPs in five textile fibers (cotton (untreated and chemically bleached), sheep's wool, polyamide, and polyester) was assessed. Herein, the fibers were first immersed in a silver ion solution $\left(1 \mathrm{~g} / \mathrm{L}\right.$ of $\left.\mathrm{AgNO}_{3}\right)$ for ion saturation at room $\mathrm{T}$ for $24 \mathrm{~h}$ followed by draining fibers and their reimmersion this time in a strong chemical reducing solution $\left(0.25 \mathrm{~g} / \mathrm{L}\right.$ of $\left.\mathrm{NaBH}_{4}\right)$ at room $\mathrm{T}$ for $24 \mathrm{~h}$. This latter step leads to the in situ formation of Ag-NPs where size $(5 \mathrm{~nm}<$ size $<50 \mathrm{~nm})$, surface covering concentration, and aggregation degree depend on the textile fiber kind as deduced from FESEM images. This simple lab chemical method allows instantaneous in situ formation of Ag-NPs onto fibers without the requirement of additional thermal treatment. Moreover, for natural fibers, the formation of Ag-NPs inside of them is also expected as confirmed from FESEM images in cotton cross sections. In complement, all textile fibers containing Ag-NPs (sheep's wool $10 \mathrm{mg} / \mathrm{g}>$ untreated cotton $2.3 \mathrm{mg} / \mathrm{g}>$ bleached cotton $1 \mathrm{mg} / \mathrm{g}>$ polyamide $0.62 \mathrm{mg} / \mathrm{g}>$ polyester $0.28 \mathrm{mg} / \mathrm{g}$ ) were submitted to interact with strong oxidants in an aqueous media $\left(7.5 \% \mathrm{v} / \mathrm{v}\right.$ of $\mathrm{H}_{2} \mathrm{O}_{2}, 0.5$ and $0.05 \mathrm{M}$ of $\mathrm{HNO}_{3}$ and ultrapure water as the control) using flow-through reactor experiments. Here, breakthrough curves reveal that the oxidative dissolution rate (given in $\mathrm{mol} / \mathrm{g} \mathrm{min}$ ) of adhered Ag-NPs (ionic release) depends strongly on fiber nature, and nature and concentration of oxidant solution. In summary, this fundamental study suggests that Ag-NPs may be successfully adhered/inserted in natural fibers (wool and cotton) in a safety-design perspective with performant biocide properties as confirmed by using Bacillus subtilis.

\section{INTRODUCTION}

With the development of nanotechnology, silver nanoparticles (Ag-NPs) are widely used due to their extraordinary optical, electrical, mechanical, catalytic, and antimicrobial properties. Moreover, silver ions and/or silver soluble compounds have been used to disinfect liquids, solids, and human tissue for centuries. ${ }^{1,2}$ Due to their effective antimicrobial activity against a wide range of microorganisms including bacteria, fungi, viruses, etc., both as colloidal suspensions and as components, Ag-NPs have gained popularity in industrial sectors including textiles, food, consumer products, medicine, etc. ${ }^{1-4}$ At the present time, Ag-NPs are extensively used in healthcare products, women's hygiene products, the food industry, paints, cosmetics, medical devices, sunscreen, biosensors, clothing, and electronics. ${ }^{1-6}$ However, this increased use of Ag-NP-improved products may cause an increase in the toxicity level, affecting both the environment and living organisms because a significant amount as $\mathrm{Ag}-\mathrm{NPs}$ or $\mathrm{Ag}^{+}$ions may be released in natural settings, ${ }^{3-7}$ but little is known about the diversified mechanisms of action of the cytotoxicity of Ag-NPs, as well as their short- or long-term exposure outcomes, on living organisms and/or human physiology. ${ }^{3-5}$ The antimicrobial activity of silver is mainly attributed to silver ions, which are released from silvercontaining compounds and interact with the thiol groups of enzymes and proteins that support microbial life, thus affecting cell respiration and killing the cells. This antimicrobial activity may be impacted/decreased by the presence of halide ions $(\mathrm{Cl}$, $\mathrm{F}$, ...) that react easily with silver ions forming precipitates. 3 Therefore, the antimicrobial activity of free silver ions is very short when they are used alone. To overcome this issue, silver nanoparticles (Ag-NPs) and Ag-NPs-containing composites have recently been developed. From these materials, silver ions are gradually released, thereby providing antimicrobial activity. ${ }^{3-5}$ In this way, to prepare the antimicrobial silver-treated textile fibers, many authors have focused their attention on the process of preparation of silver nanoparticles with controlled size and on developing methods to attach the Ag-NPs not only on the surface of fibers but also inside them..$^{8-15}$ Generally, AgNPs have low energetic adherence onto fibers when they are produced ex situ and inserted physically or by using conventional physicochemical methods (e.g., pad-dry cure method). In order to overcome this recurrent problem of adherence, the in situ formation of Ag-NPs in textile fibers is also being developed. ${ }^{8,9,12}$ Many other studies have been focused on the surface examination using the modern instrumental methods

Received: October 1, 2020

Accepted: November 16, 2020

Published: January 5, 2021 

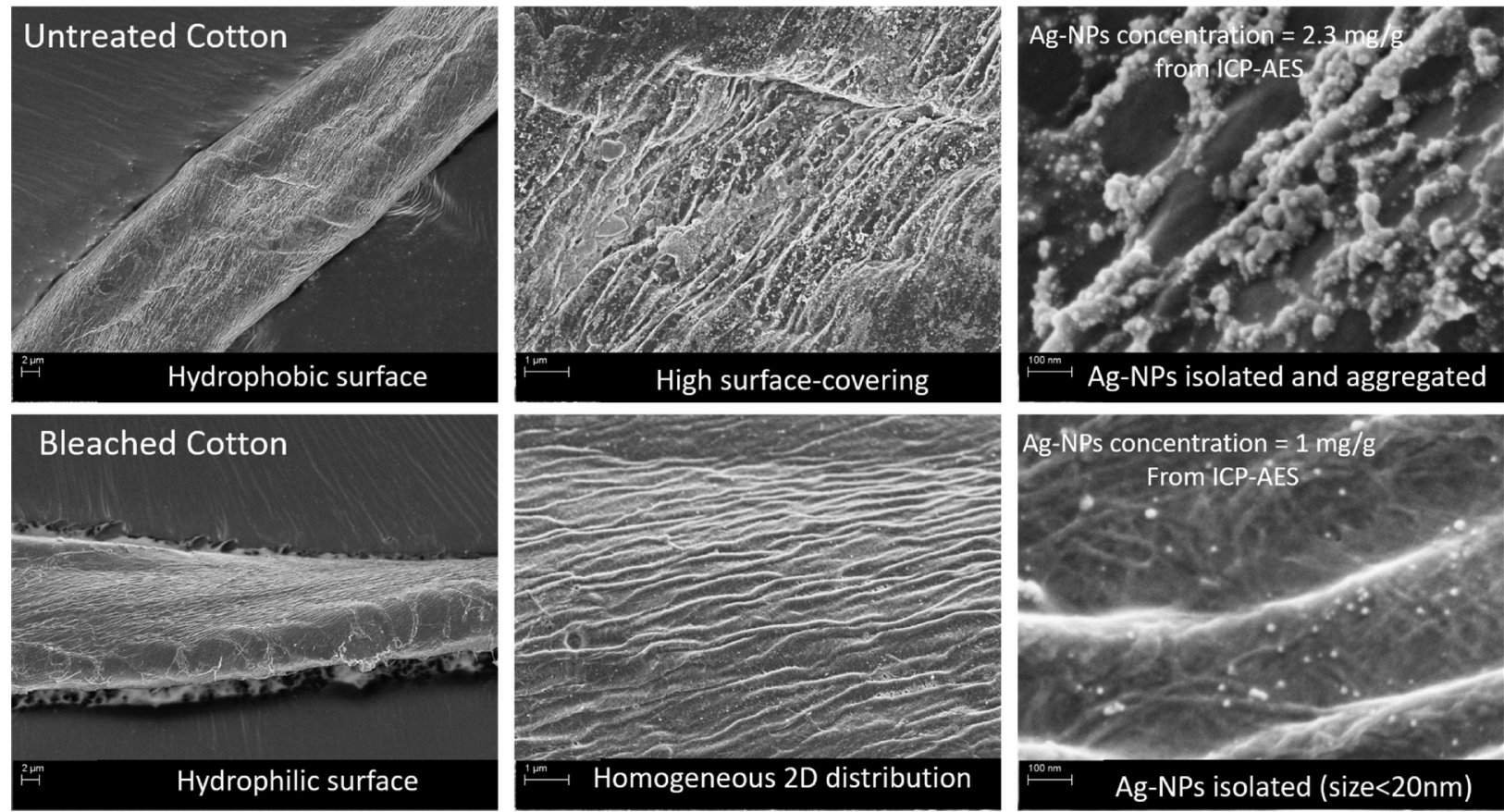

Figure 1. FESEM images at three different magnifications showing size, shape, aggregation degree, and 2D distribution of in situ formed Ag-NPs onto untreated and bleached cotton fibers. Ag-NPs concentration was also determined by ICP-AES in digested fibers containing Ag-NPs as explained in the Materials and Methods section.

and compared to conventional antibacterial efficacy as well as to its durability against multiple washings in the alkaline bath (detergents with or without oxidants). ${ }^{5,6,16-22}$ The current study reports more fundamental research on the in situ formation of silver nanoparticles (Ag-NPs) onto/into five textile fibers (cotton (untreated and chemically bleached), sheep's wool, polyamide, and polyester) with different surface properties, such as hydrophobicity, roughness, and porosity. Herein, two sequential reaction steps were performed: first, the fibers were immersed in a silver ion solution $\left(1 \mathrm{~g} / \mathrm{L}\right.$ of $\left.\mathrm{AgNO}_{3}\right)$ for ion saturation followed by draining fibers and their reimmersion this time in a strong chemical reducing solution $(0.25 \mathrm{~g} / \mathrm{L}$ of $\left.\mathrm{NaBH}_{4}\right)$. This latter step leads to the in situ formation of Ag-NPs $(<50 \mathrm{~nm})$, average size and surface covering concentration depend on the fiber kind as deduced from FESEM images. $\mathrm{NaBH}_{4}$ have strong reduction potential, and then it allows instantaneous in situ formation of Ag-NPs onto/into fibers at room temperature without the requirement of additional thermal treatment as documented in the literature, but several other reducing agents exist and have been investigated. ${ }^{2,23,24}$ In complement, all textile fibers containing Ag-NPs were submitted to interact with strong oxidants in an aqueous media $(7.5 \% \mathrm{v} / \mathrm{v}$ of $\mathrm{H}_{2} \mathrm{O}_{2}$ and $0.5 \mathrm{M}$ of $\mathrm{HNO}_{3}$ ) using flow-through reactor experiments in order to determine if textile fiber kind plays a significant role on the oxidation rate of adhered Ag-NPs under extreme conditions. This unconventional method allows then a fast assessment of the oxidative dissolution rate of Ag-NPs adhered/inserted by the same in situ chemical reduction method in different textile fibers. Moreover, under these extreme oxidative conditions, the surface of fibers is expected to be rapidly altered similarly to multiple washing cycles. Concentration of $\mathrm{Ag}$ in textile fibers and in sampled solutions during flow-through reactor experiments was quantified by ICP-AES analysis. Conventional biotests using the Bacillus subtilis strain for all textile fibers containing Ag-NPs were also performed.

\section{RESULTS AND DISCUSSION}

In situ formation of Ag-NPs was investigated by chemical reduction of silver ions initially saturating five different textile fibers (see overall reduction of reaction 1 in the Materials and Methods section). As expected, average size of Ag-NPs, aggregation degree, and surface covering concentration depend strongly on the textile fiber nature as revealed here by FESEM images.

Untreated Cotton versus Bleached Cotton. The insertion of Ag-NPs onto cotton fibers has been widely investigated, particularly using cotton fabrics and using various physicochemical methods. ${ }^{8,12,16}$ Herein, the low adherence of Ag-NPs onto cotton fibers remains the main limitation because a significant number of Ag-NPs can be released in the first washing cycles. ${ }^{18,22}$ In the present study, untreated cotton (initially hydrophobic fibers) and bleached cotton (hydrophilic fibers available in pharmacies) were preferentially used in order to determine the role of initial surface properties. At a micrometric scale, the fibers seem very similar in texture (shape and rugosity). Conversely, at a nanometric scale, the bleached cotton seems porous and with higher rugosity (see Figure 1). These different surface properties have constrained the surface covering concentration and aggregation degree of in situ formed Ag-NPs. In both cases, very fine Ag-NPs (size $<20 \mathrm{~nm}$ ) were in situ formed, but high aggregation degree and higher surface covering concentration were observed for untreated cotton from FESEM images (Figure 1). Quantitative measurements by ICPAES of digested fibers containing Ag-NPs have confirmed a higher silver concentration for untreated cotton $(2.3 \mathrm{mg}$ of $\mathrm{Ag} / \mathrm{g}$ of cotton) and only $1 \mathrm{mg} / \mathrm{g}$ for bleached cotton. This surprising result is probably related to the lower adherence of Ag-NPs onto bleached cotton as suspected during the washing step of fibers with ultrapure water where more washing times were required to remove unadhered Ag-NPs with respect to all other investigated fiber kinds (see also Figure S1). However, biotests based on 


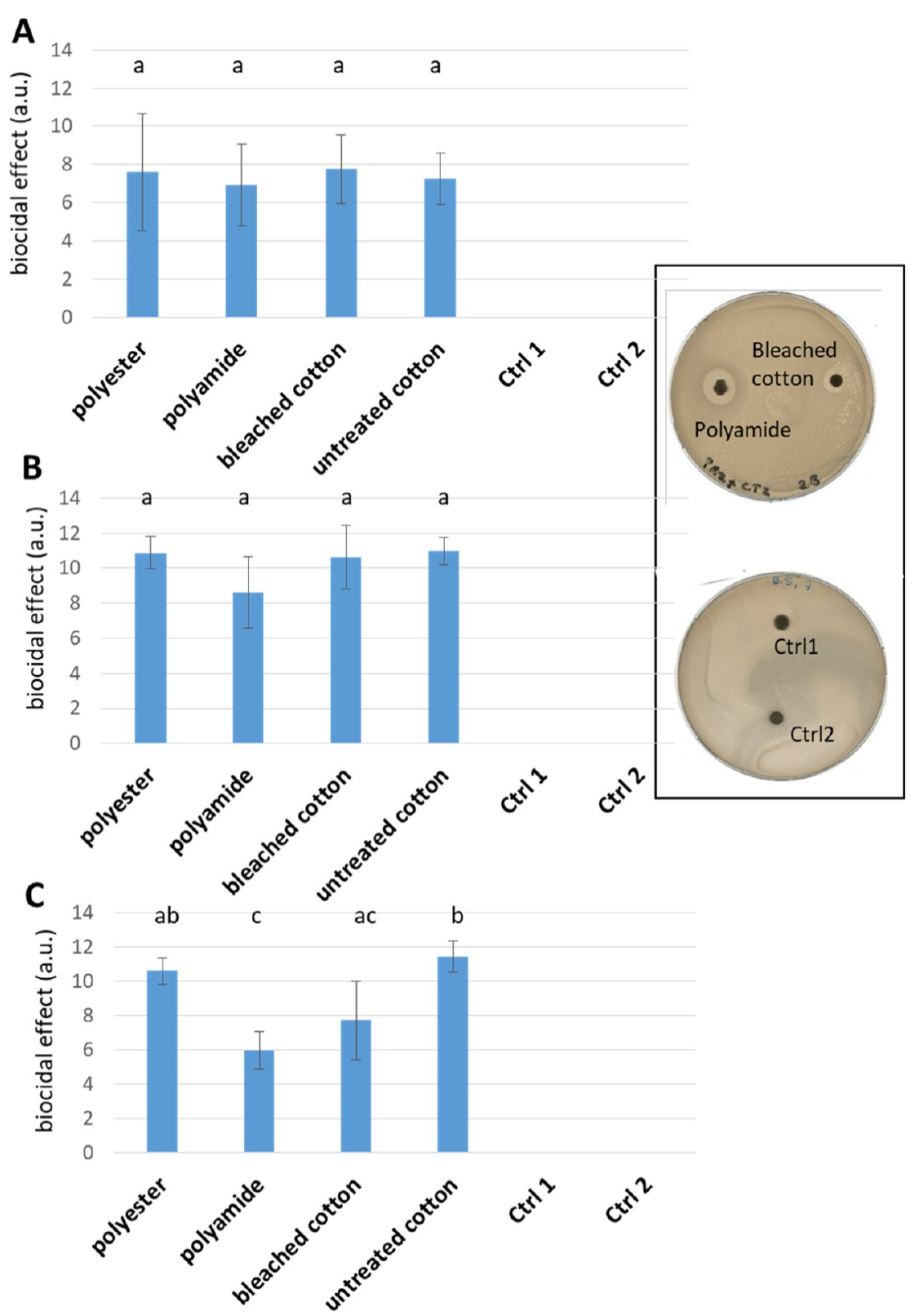

Figure 2. Evaluation of the biocidal properties of the fibers using a biotest after 24,48 , and $72 \mathrm{~h}$ of contact with the pellet (A, B, and C, respectively). Representative photos of the agar plate with pellets of impregnated polyamide and bleached cotton and their inhibition halo, and of the agar plate with control cotton are shown.

Bacillus subtilis growth inhibition on agar plates reveal equivalent biocidal potential of the impregnated fibers at 24 and $48 \mathrm{~h}$, but untreated cotton had a stronger biocidal effect than bleached cotton at $72 \mathrm{~h}$ as summarized in Figure 2. This means that AgNP concentration can play a significant role in longer durations. Ag-NPs' antimicrobial property is mainly mediated by released $\mathrm{Ag}^{+}$ions from Ag-NPs, which penetrate bacterial cells and inhibit the cell metabolism as widely described in specialized studies. $^{25,26}$

The developing methods to attach the Ag-NPs not only on the surface of fibers but also inside them remain an important challenge. In this way, cross sections of bleached cotton were prepared and observed by FESEM, which confirms the formation of Ag-NPs inside of the fibers (see Figure 3). Here, isolated nanoparticles with regular size $(<20 \mathrm{~nm})$ and spherical shape were homogeneously inserted into the cotton fibers. Similar results may be expected in other natural porous fibers, such as wool, silk, and cellulose, by using our in situ formation method. However, a deeper investigation on the Ag-NPs' adherence and reactivity remains to be performed in the future. In the present study, for example, the bleached cotton allows better distribution of isolated Ag-NPs onto and inside the fibers; however, lower adherence is suspected because using identical chemical treatment and the same mother solutions, the untreated cotton has sequestered a higher number of Ag-NPs as revealed by FESEM images and quantified by ICP-AES. This means that the conventional bleaching treatment in cotton fibers have modified the surface functionality to bond the Ag-NPs.

The reactivity of adhered Ag-NPs in strong oxidant solutions was also investigated by using flow-through reactor experiments (see Figure S2). Herein, the oxidative dissolution rate is directly proportional to the outlet concentration of $\mathrm{Ag}$ (see eq 2). The obtained breakthrough curves for bleached cotton have revealed that the oxidative dissolution rate of adhered Ag-NPs (ionic 

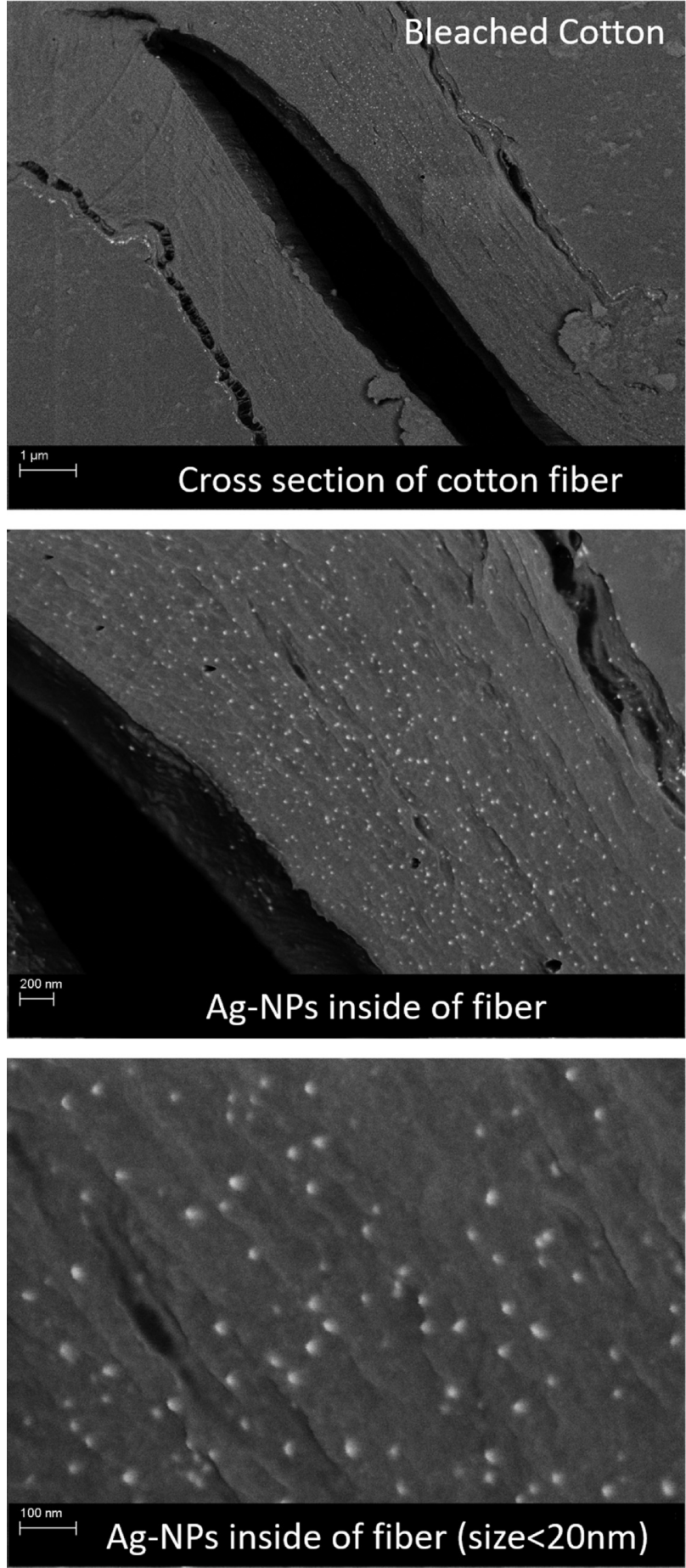

Figure 3. FESEM images of a given cross section for bleached cotton showing that the Ag-NPs were also formed inside of the fiber.

release) is 3-4 times higher in oxygenated water $(7.5 \% \mathrm{v} / \mathrm{v})$ than in nitric acid $(0.5 \mathrm{M})$ (see Figure 4$)$. In both cases, the $\mathrm{Ag}$ release (outlet concentration) tends toward zero after $24 \mathrm{~h}(\mathrm{Ag}$ outlet concentration $=0.017 \mathrm{mg} / \mathrm{L}$ in nitric acid and $0.002 \mathrm{mg} / \mathrm{L}$ in oxygenated water). This means that the initially available AgNPs are almost completely dissolved in the system. Conversely, the Ag-NPs adhered onto untreated cotton are slowly dissolved in oxygenated water reaching a steady state (dissolution rate, $r=$ $1.6945 \times 10^{-6} \mathrm{~mol} / \mathrm{g} \mathrm{min}$ ) after about $20 \mathrm{~h}$ of continuous solution percolation; however, they are highly dissolved in nitric acid solution reaching a maximum dissolution rate after $2 \mathrm{~h}(r=$ $\left.1.5474 \times 10^{-5} \mathrm{~mol} / \mathrm{g} \mathrm{min}\right)$ and a steady state $\left(r=5.3750 \times 10^{-7}\right.$ $\mathrm{mol} / \mathrm{g} \mathrm{min}$ ) after about $20 \mathrm{~h}$ of continuous solution percolation in the system (Figure 4). These interesting results have revealed that the reactivity of in situ formed Ag-NPs onto cotton fibers depends on the initial textural and physicochemical properties of fibers. Based on these results, we conclude that untreated cotton fibers offer a better option to insert Ag-NPs by in situ chemical reduction of silver ions in a safety-design perspective. We note that the investigated oxidative conditions (extremes) and our experimental setup have not represented realistic reactive scenarios with respect to durability and release of $\mathrm{Ag}-\mathrm{NPs}$ from textile commercialized fabrics, but our approach allows a simple assessment of the oxidative dissolution rate of Ag-NPs directly related to the initial textural and physicochemical properties of textile fibers. Based on these above results, we claim that the ionic release of $\mathrm{Ag}$ and $\mathrm{AgNPs}$ detachment can strongly depend on surface physicochemical properties as confirmed in the following other cases.

Sheep's Wool. Commercial sheep's wool fibers have high rugosity and seem porous at a nanometric scale (see Figure 5). These textural surface properties have allowed an extraordinary adherence of in situ formed Ag-NPs as revealed from FESEM images. Here, very fine spherical Ag-NPs $($ size $<20 \mathrm{~nm})$ were homogeneously precipitated with a low aggregation degree and with high surface covering concentration (Figure 5). The high Ag-NP concentration was confirmed by ICP-AES analysis in digested $\mathrm{Ag}$-containing fibers $(10 \mathrm{mg} / \mathrm{g})$, i.e., 10 times more concentrated than bleached cotton and about four times more concentrated than untreated cotton. In summary, wool fibers have ideal surface properties to successfully insert Ag-NPs with high physicochemical adherence by using our in situ chemical reduction method. The high physicochemical adherence of in situ formed Ag-NPs may be related to the strong chemical affinity of Ag ions into wool fibers, i.e., a strong attachment with pre-existent functionalized groups (carboxyl $(-\mathrm{COOH})$, amino $\left(-\mathrm{NH}_{2}\right)$, and hydroxyl $(-\mathrm{OH})$ ) before its in situ chemical reduction as already invoked by Mahmud et al. ${ }^{10}$ In this way, the ATR-FTIR analysis of five wool samples, pure and subject to oxidant solutions, are shown in Figure S3 of the Supporting Information. Results for the Ag-free wool and Ag-rich wool are shown in Figure 6. Here, the ATR-FTIR spectrum of Ag-free wool shows a broad peak around $3250 \mathrm{~cm}^{-1}$ corresponding to stretching $\mathrm{O}-\mathrm{H}$ modes of adsorbed water and a set of vibrational modes characteristic of keratin, the main protein in wool: $-\mathrm{CH}_{2}$ and $-\mathrm{CH}_{3}$ stretching vibrations of the polypeptide backbone of the fibers; $-\mathrm{CH}_{2}$ at $1620 \mathrm{~cm}^{-1}$ (amide I); $\mathrm{C}-\mathrm{N}$ stretching and $\mathrm{N}-\mathrm{H}$ bending at $1520 \mathrm{~cm}^{-1}$ (amide II); and C$\mathrm{N}, \mathrm{C}-\mathrm{O}$ stretching, and $\mathrm{N}-\mathrm{H}$ bending at $1230 \mathrm{~cm}^{-1}$ (amide III). ${ }^{27-29}$ The peak at $1040 \mathrm{~cm}^{-1}$ corresponds to a stretching vibrational mode of cysteine oxides. ${ }^{27}$

Upon in situ deposition of Ag-NPs and washing with water, three main changes are observed in the ATR-FTIR spectra:

(i) The $-\mathrm{CH}_{2}$ and $-\mathrm{CH}_{3}$ stretching bands at 2850 and 2920 $\mathrm{cm}^{-1}$ decrease in intensity. The band at $2920 \mathrm{~cm}^{-1}$ is shifted to $2930 \mathrm{~cm}^{-1}$.

(ii) The intensity of the bands at $1415 \mathrm{~cm}^{-1}$ and $1195 \mathrm{~cm}^{-1}$, corresponding to the amide II region, decrease in intensity.

(iii) The peak at $1024 \mathrm{~cm}^{-1}$ disappears. This peak has been attributed to stretching vibrations in cysteine-s-sulphonate groups, present in keratin. ${ }^{27}$ Other studies have also 

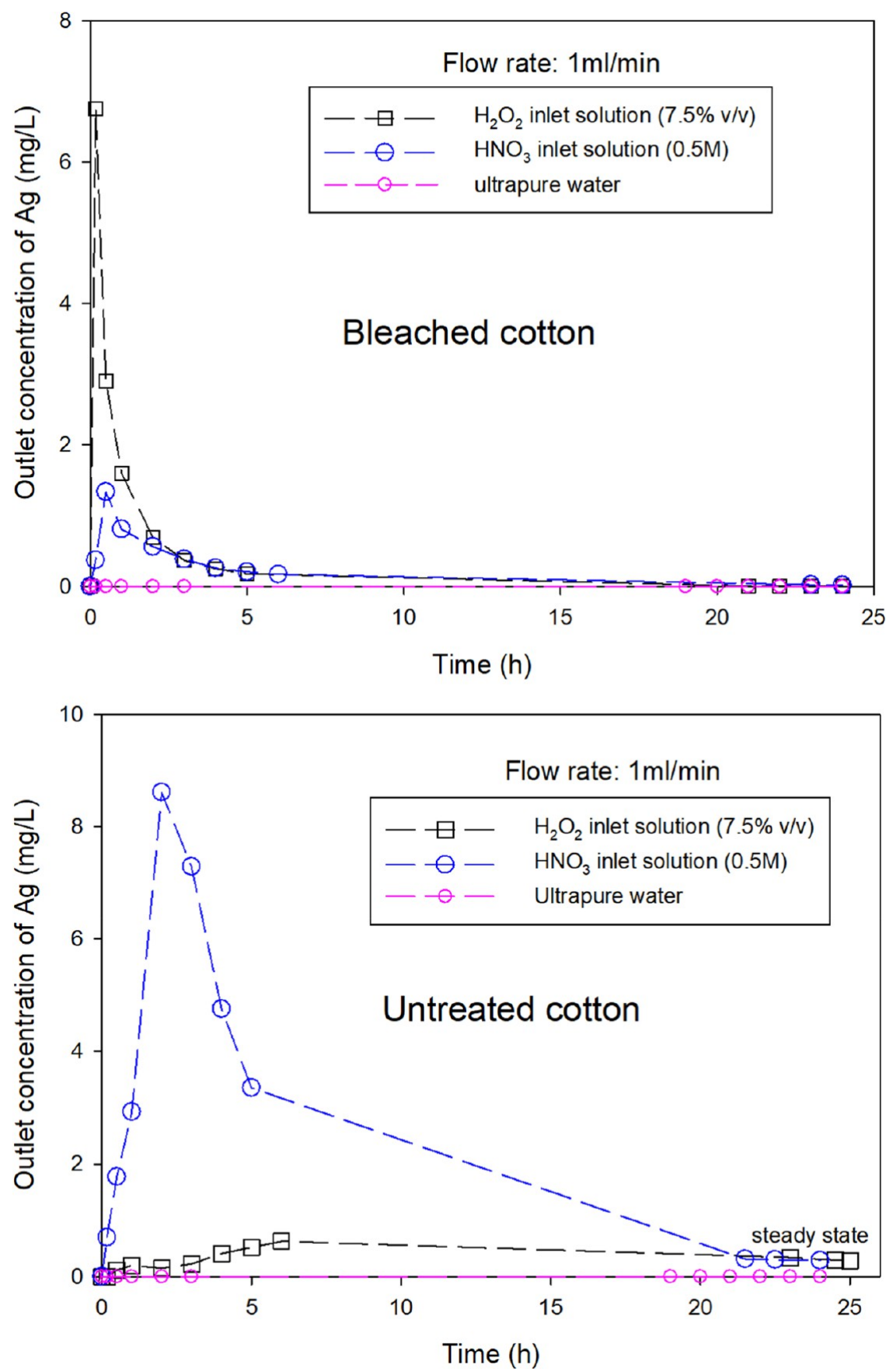

Figure 4. Breakthrough curves showing the oxidative release of $\mathrm{Ag}$ as a function of time obtained from flow-through reactor experiments. Inlet solutions: ultrapure water (control), oxygenated water $(7.5 \% \mathrm{v} / \mathrm{v})$, and nitric acid solution $(0.5 \mathrm{M})$; Ag-NPs adhered onto bleached and untreated cotton fibers, flow rate of $1 \mathrm{~mL} / \mathrm{min}$ and $\mathrm{Ag}$ outlet concentration measured by ICP-AES.

identified this group in residues from Bunte salts that are used as coatings of the wool fibers. ${ }^{30}$

Overall, these results point to Ag-NPs and polypeptide interactions, with little interaction with the amide components, suggesting noncomplexing interactions between the nanoparticles and the keratin fibers.

Additionally, flow-through reactor experiments have revealed undetected reactivity of Ag-NPs when ultrapure water was percolated in the system (see Figure 7). This means that Ag-NPs were successfully attached onto/into wool surfaces. Concerning the strong oxidant solutions, the oxidative dissolution rate of AgNPs depends on the concentration and chemical nature of the oxidant solutions (see Figure 7). In general, higher dissolution rates were measured in the first $5 \mathrm{~h}$ of continuous percolation, reaching a steady state after about $20 \mathrm{~h}$. In chronological order, the Ag-NPs adhered/inserted in wool fibers are most reactive in oxygenated water $\left(2.1037 \times 10^{-6} \mathrm{~mol} / \mathrm{g} \mathrm{min}\right)$ followed by nitric acid $\left(6.5319 \times 10^{-7} \mathrm{~mol} / \mathrm{g} \min\right.$ for $0.5 \mathrm{M}$ of $\left.\mathrm{HNO}_{3}\right)$, and $\left(5.3750 \times 10^{-7} \mathrm{~mol} / \mathrm{g} \min\right.$ for $0.05 \mathrm{M}$ of $\left.\mathrm{HNO}_{3}\right)$. This unconventional assessment suggests that the wool fibers offer an excellent potential to adhere Ag-NPs by a simple in situ chemical reduction method as also supported by FTIR results in this study. This suggests that the Ag release from doped wool fibers is related only to the silver oxidation process and the particulate 

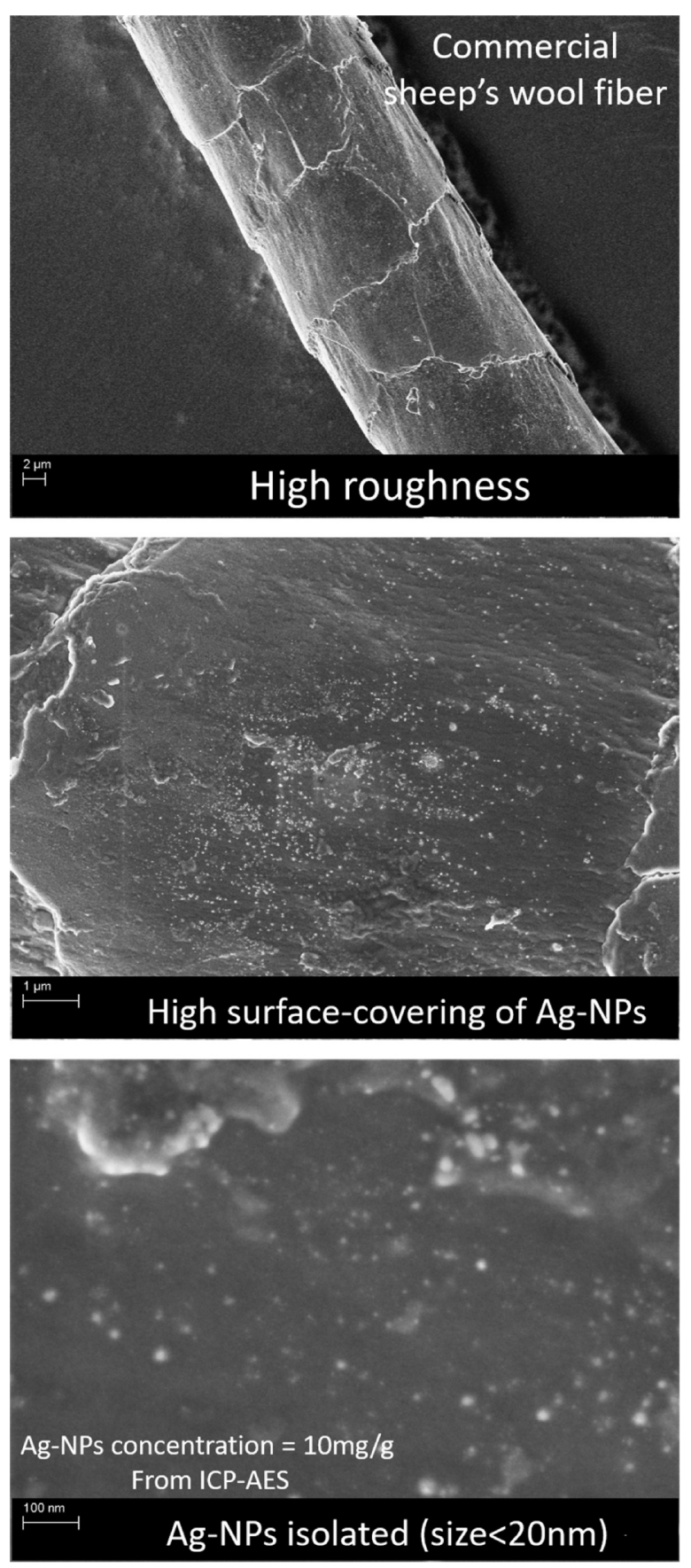

Figure 5. FESEM images at three different magnifications showing size, shape, aggregation degree, and $2 \mathrm{D}$ distribution of in situ formed $\mathrm{Ag}$ NPs onto commercial sheep's wool fiber. Ag-NPs concentration was also determined by ICP-AES in digested fibers containing Ag-NPs as explained in the Material and Methods section.

detachment will be minimized despite the physicochemical alteration of fibers as illustrated on FESEM images obtained after the flow-through reactor experiment (Figure 8). Herein, FESEM images have revealed localized physicochemical alteration of fibers (bleaching and cracking in oxygenated water) and localized/zoned reactivity of Ag-NPs. This is probably related to different bond forces that is exerted by different existent functionalized groups, such as carboxyl $(-\mathrm{COOH})$, amino $(-\mathrm{NH} 2)$, and hydroxyl $(-\mathrm{OH}),{ }^{10}$ as suspected from FTIR measurements where alteration of wool fibers was also detected (see Figure S3).
Polyamide versus Polyester. Polyamide and polyester textile fibers are nonporous, and they have lower roughness at a nanometric scale with respect to natural textile fibers (see Figure 9). Moreover, they have typically low hydrophilic properties (fast expelling of water). Despite these surface properties, a significant number of Ag-NPs were adhered onto these synthetic textile fibers by in situ chemical reduction of $\mathrm{Ag}$ ions. For polyamide, the Ag-NPs were preferentially nucleated in the continuous cavities on the fiber, leading to oriented nucleation of Ag-NPs with spherical shape and small size $(<20 \mathrm{~nm})$. High surface covering concentration was then observed on the curved longitudinal cavities, but scarce Ag-NPs were nucleated and attached on the little rough surfaces (see Figure 9). Quantitative measurements by ICP-AES in digested Ag-containing polyamide fibers have revealed $0.62 \mathrm{mg}$ of $\mathrm{Ag} / \mathrm{g}$ of fibers, this agrees with FESEM observations. Conversely, the Ag-NPs have lower adherence onto the surface of polyester fibers. Here, the identified surface cavities are not necessarily reactive sites because the heterogeneous nucleation of Ag-NPs seems to be mainly associated to roughness (see Figure 9). In this case, lower surface covering concentration was identified from FESEM images with respect to polyamide and natural fibers. This agrees with quantitative results from ICP-AES analysis that reveals only $0.28 \mathrm{mg}$ of $\mathrm{Ag} / \mathrm{g}$ of polyester fibers. In summary, synthetic textile fibers offer poor surface properties to insert Ag-NPs with strong adherence by in situ chemical reduction of silver ions. For this reason, the insertion of high concentration ( $>1 \%)$ of Ag-NPs in synthetic textile fibers with antimicrobial properties is typically fabricated by using an electrospinning production method where generally the Ag-NPs are added into polymer solutions or polymer melts that are then injected and subjected to an electric force. $^{31-34}$

Obviously, the investigated synthetic fibers have offered poor textural properties to adhere effectively the Ag-NPs by using our in situ chemical formation method. For example, polyamide fibers have adhered $0.62 \mathrm{mg}$ of $\mathrm{Ag} / \mathrm{g}$ of polyamide fibers (see also Figure 9). This represent a non-negligible amount, but a lower adherence force between Ag-NPs and polyamide fibers is suspected because detectable Ag concentration $(0.013 \mathrm{mg} / \mathrm{L})$ was measured in outlet solution after $10 \mathrm{~min}$ when ultrapure water was percolated; this is probably related to particulate detachment. This disagrees with all other experiments performed with ultrapure water concerning cotton and wool fibers where an undetected $\mathrm{Ag}$ signal was measured. In addition, a fast oxidative dissolution rate $\left(2.6077 \times 10^{-5} \mathrm{~mol} / \mathrm{g} \mathrm{min}\right)$ was also measured in the first $10 \mathrm{~min}$ when nitric acid solution was percolated; then, the Ag release decreases abruptly and tends toward zero $(0.029 \mathrm{mg} / \mathrm{L})$ after $24 \mathrm{~h}$ (see Figure 10). These results suggest that in the first hour, the measured $\mathrm{Ag}$ in outlet solutions may be a contribution of detached Ag-NPs and ionic Ag. Then, the kinetic oxidative dissolution follows similar behavior to Ag-NPs adhered on the bleached cotton fibers (Figure 10).

In summary, natural textile fibers offer better surface textural and physicochemical properties to adhere/insert Ag-NPs by in situ chemical reduction of silver ions with respect to synthetic fibers. However, a conventional biotest based on Bacillus subtilis growth inhibition on agar plates confirmed the biocidal properties for all impregnated fibers compared to the control (Figure 2). In general, at 24 and $48 \mathrm{~h}$, no significant difference was observed between the fibers, whereas at $72 \mathrm{~h}$, polyester and untreated cotton had a stronger biocidal effect than polyamide and bleached cotton was intermediate. 

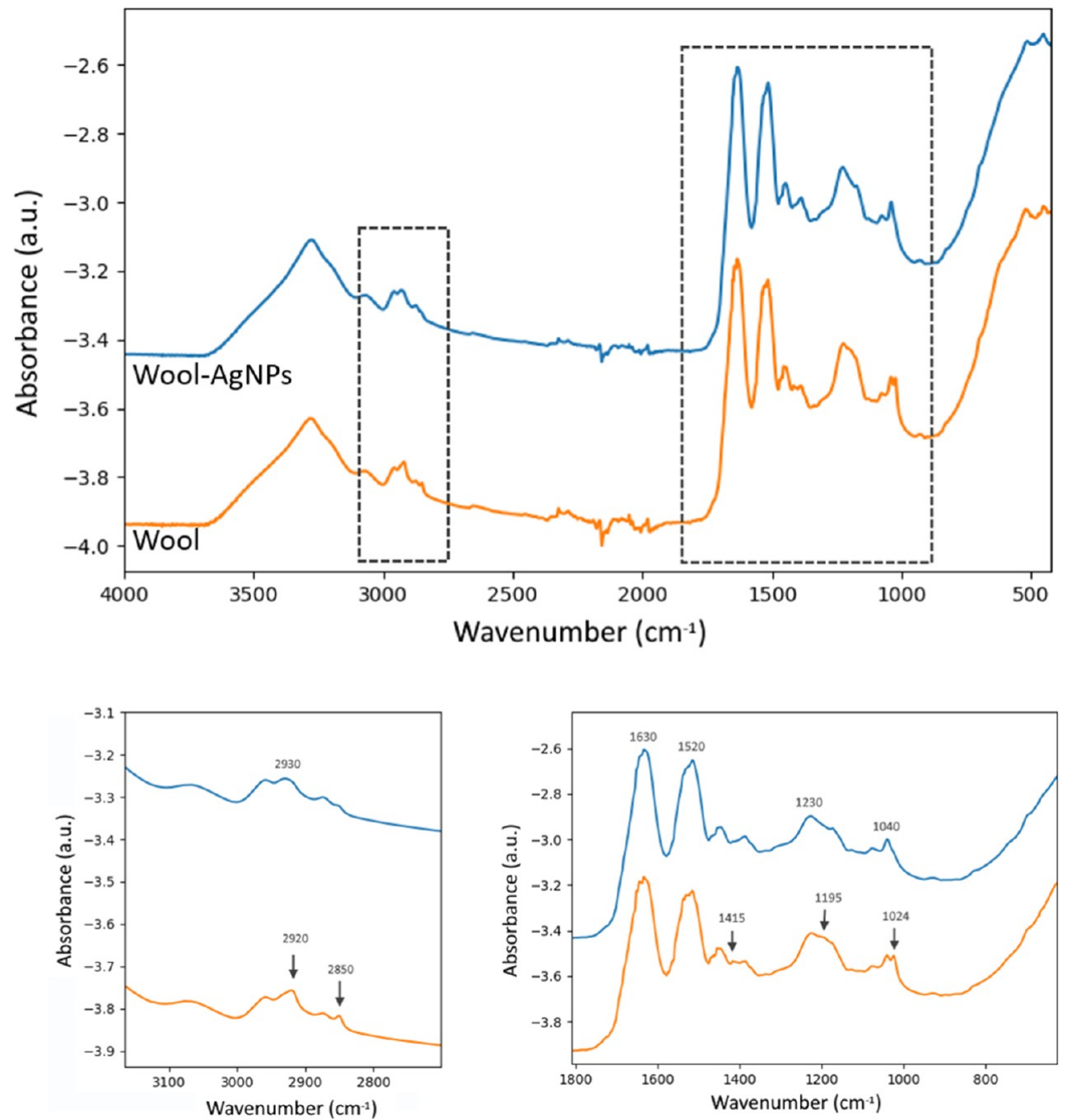

Figure 6. ATR-FTIR spectra for Ag-free wool and wool containing Ag-NPs. $-\mathrm{CH}_{2}$ and $-\mathrm{CH}_{3}$ stretching bands at 2850 and $2920 \mathrm{~cm}^{-1} ;-\mathrm{CH}_{2}$ at 1620 (amide I), C-N stretching, and $\mathrm{N}-\mathrm{H}$ bending at $1520 \mathrm{~cm}^{-1}$ (amide II); and $\mathrm{C}-\mathrm{N}, \mathrm{C}-\mathrm{O}$ stretching, and $\mathrm{N}-\mathrm{H}$ bending at $1230 \mathrm{~cm}^{-1}$ (amide III). The peak at $1040 \mathrm{~cm}^{-1}$ corresponds to a stretching vibrational mode of cysteine oxides.

\section{CONCLUSIONS}

We report that the in situ formation of silver nanoparticles (Ag$\mathrm{NPs}$ ) onto textile fibers by chemical reduction of sequestered $\mathrm{Ag}$ ions can be a powerful chemical method to adhere/insert AgNPs onto/into textile fibers in a successfully safety-design perspective. Herein, the wool fibers offer the best effectiveness to adhere Ag-NPs $(10 \mathrm{mg} / \mathrm{g})$ followed by the untreated cotton 2.3 $\mathrm{mg} / \mathrm{g}>$ bleached cotton $1 \mathrm{mg} / \mathrm{g}>$ polyamide $0.62 \mathrm{mg} / \mathrm{g}>$ polyester $0.28 \mathrm{mg} / \mathrm{g}$. In all cases, spherical Ag-NPs (size < 20 $\mathrm{nm}$ ) were formed when their aggregation degree and surface covering concentration was controlled by pre-existent surface and physicochemical properties, such as hydrophilicity, roughness, porosity, functionality, etc. All fibers containing Ag-NPs provide biocide properties, but the ionic $\mathrm{Ag}$ release and $\mathrm{Ag}$ nanoparticle detachment depend strongly of the fiber nature. For example, Ag-NPs interactions with strong oxidant solutions by using flow-through reactor experiments suggest an effective adherence of Ag-NPs onto fibers and controlled ionic release for natural fibers, particularly for wool and untreated cotton, because low oxidative dissolution rates (an order of $1 \times 10^{-7}$ $\mathrm{mol} / \mathrm{g} \mathrm{min}$ ) were determined when the steady state is reached under extreme oxidant conditions. This can ensure an optimized durability and antimicrobial effectiveness of textile fibers. However, as commented in the introduction, several unknown risks exist on the release and fate of Ag-NPs and $\mathrm{Ag}$ ions in natural settings. In this way, we suggest that the use of Ag-NPs onto/into natural and/or synthetic fibers with antimicrobial activity should be limited to specific essential applications, such as medical devices and healthcare worker protection rather than an extended application to not essential applications such as sport clothings for example.

\section{MATERIALS AND METHODS}

In Situ Formation of Ag-NPs onto Textile Fibers. Three grams of five commercial textile fibers (untreated cotton (hydrophobic), chemically bleached cotton (hydrophilic), sheep's wool (hydrophobic), polyamide (from sport socks), and polyester (from sport hat)) were initially immersed in 250 $\mathrm{mL}$ of $\mathrm{AgNO}_{3}$ solution $(1 \mathrm{~g} / \mathrm{L})$ for $24 \mathrm{~h}$. This simple treatment allows the silver ion saturation of fibers. Then, the fibers are manually drained and immersed in $250 \mathrm{~mL}$ of $\mathrm{NaBH}_{4}$ reducing solution $(250 \mathrm{mg} / \mathrm{L})$. Instantaneous silver reduction was attested by a color change from uncolored to black; the overall redox reaction may be written as follows: 


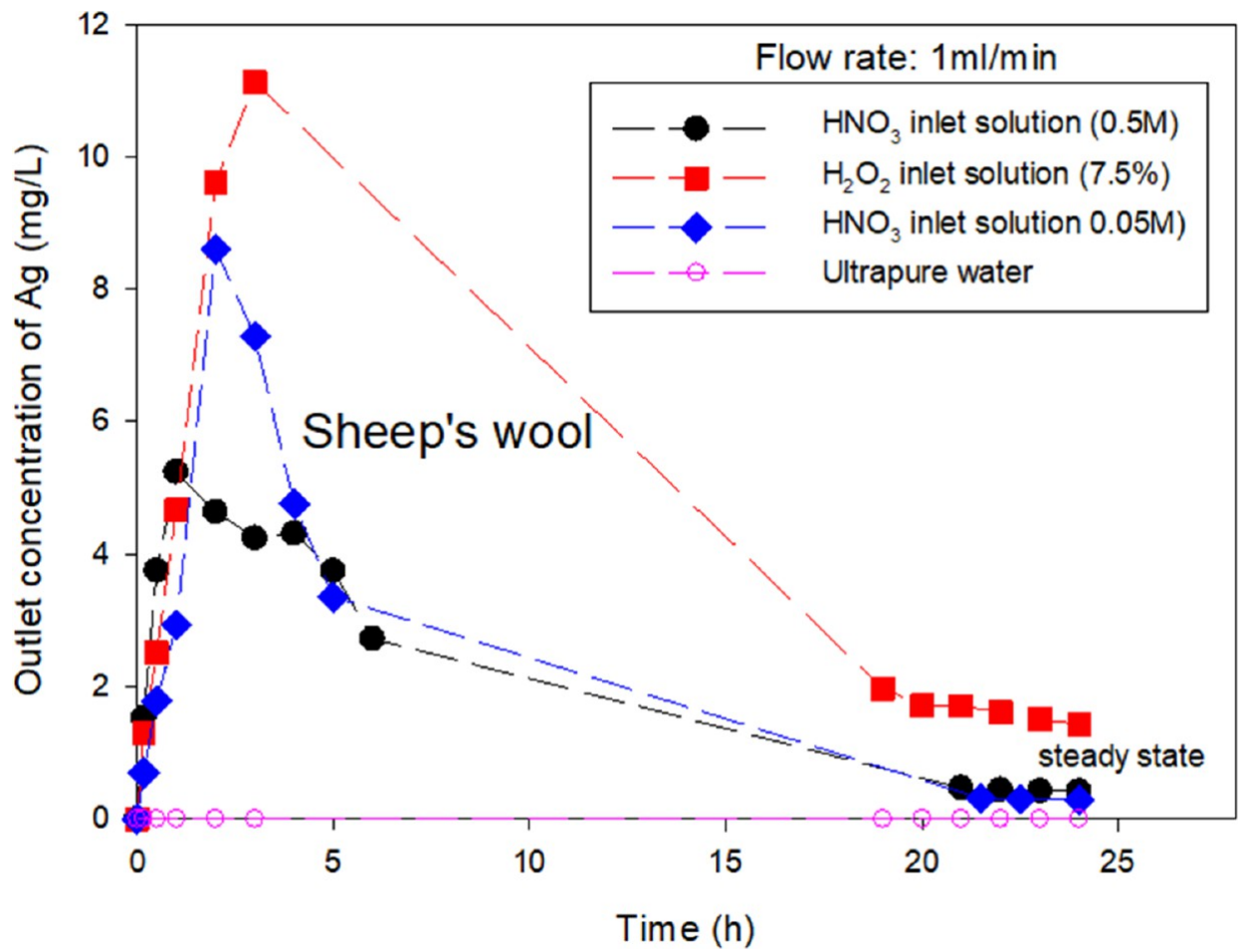

Figure 7. Breakthrough curves showing the oxidative release of $\mathrm{Ag}$ as a function of time obtained from flow-through reactor experiments. Inlet solutions: ultrapure water (control), oxygenated water ( $7.5 \% \mathrm{v} / \mathrm{v})$, and nitric acid solutions ( 0.5 and $0.05 \mathrm{M})$; Ag-NPs adhered onto sheep's wool fibers, flow rate of $1 \mathrm{~mL} / \mathrm{min}$ and $\mathrm{Ag}$ outlet concentration measured by ICP-AES.

$$
\begin{aligned}
& \mathrm{AgNO}_{3}+\mathrm{NaBH}_{4} \\
& \quad \Rightarrow \mathrm{Ag}^{0}+0.5 \mathrm{H}_{2}+0.5 \mathrm{~B}_{2} \mathrm{H}_{6}+\mathrm{NaNO}_{3}
\end{aligned}
$$

The interaction system was arbitrary prolonged for $24 \mathrm{~h}$ at room temperature $\left(\sim 20^{\circ} \mathrm{C}\right)$ in order to ensure a total silver reduction and equilibration of the system (nucleation and maturation of particles). Then, the fibers were recovered and washed various times with ultrapure water (18.2 $\mathrm{M} \Omega$ of resistivity) in order to remove all no-adhered Ag-NPs (Figure S1). Finally, the fibers were drained, dried at $60{ }^{\circ} \mathrm{C}$ for $72 \mathrm{~h}$, and stored for subsequent characterization and experiments.

FESEM Observations. All fiber samples were carefully attached on double-sided conductive adhesive supported in aluminum SEM supports and coated with gold-platinum $(\mathrm{Au}-$ $\mathrm{Pt}$ ). The shape and size of crystals and their $2 \mathrm{D}$ distribution onto fibers were then observed by using a Zeiss Ultra 55 field emission gun scanning electron microscope (FESEM) with a maximum spatial resolution of approximately $1 \mathrm{~nm}$ at $15 \mathrm{kV}$.

In addition, some cotton fibers were immerged in epoxy resin and finally sectioned and polished transversally in order to determine if Ag-NPs are also formed inside of fibers.

Total Ag Content in Fibers. About $30-40 \mathrm{mg}$ (in triplicate) of each fiber containing adhered Ag-NPs were digested (total dissolution) by adding $15 \mathrm{~mL}$ of ultrapure $\mathrm{HNO}_{3}$ at $70 \%$ and heated at $180{ }^{\circ} \mathrm{C}$ for $20 \mathrm{~min}$ in a microwave system (Novawave, SCP Sciences). Samples were then diluted by the addition of $10 \mathrm{~mL}$ of ultrapure water. ICP-AES measurements were performed by using a Varian 720ES at ISTerre, using the Ag lines at 328 and $338 \mathrm{~nm}$.

Reactivity of Adhered Ag-NPs in Strong Oxidant Solutions. To track the oxidation rate of adhered Ag-NPs on textile fibers under extreme conditions, one stirred flow-through reactor was used. Herein, $0.7 \mathrm{~g}$ of a given fiber containing Ag-
NPs were placed in the reactor of $50 \mathrm{~mL}$ (internal volume), and it was first filled with ultrapure water $(18.2 \mathrm{M} \Omega)$. Then, flow rate calibration and washing during $10-20 \mathrm{~min}$ using a peristaltic pump, a given oxidant solution $\left(7.5 \% \mathrm{v} / \mathrm{v}\right.$ of $\mathrm{H}_{2} \mathrm{O}_{2}, 0.5 \mathrm{M}$ of $\mathrm{HNO}_{3}$ or ultrapure water $(18.2 \mathrm{M} \Omega)$ ) was percolated in the reactor using a constant flow rate of $1 \mathrm{~mL} / \mathrm{min}$ (Q). The interacting solution in the reactor was continuously stirred (150 $\mathrm{rpm})$ by a magnetic Teflon bar at room temperature $\left(\sim 20^{\circ} \mathrm{C}\right)$. The outflow solution was filtered in situ through a $0.2 \mu \mathrm{m}$ pore size Teflon membrane (located on the top of the reactor); the experimental setup is illustrated in Figure S2. The filtered solutions at various times $(10,30,60,120,180, \ldots, 1440 \mathrm{~min})$ of the experiment were then analyzed by ICP-AES by using a Varian 720 ES at ISTerre.

The inlet strong oxidant solution does not contain dissolved silver ions; in this case, the silver concentration in the outflow solution, $[\mathrm{Ag}]_{\text {out }}$, provides a direct measure of the rate of Ag-NP dissolution when a steady state is reached.

$$
r=\frac{Q[\mathrm{Ag}]_{\mathrm{out}}}{m_{\mathrm{AgNPs}}}
$$

where the rate, $r$, may be given in $\mathrm{mol} / \mathrm{g}$ min. In our case, the available amount of $\mathrm{Ag}$ into the reactor can be a limiting factor, which means the available number of Ag-NPs could be completely removed from the system by oxidative dissolution when $[\mathrm{Ag}]_{\text {out }}$ tends toward 0 .

Characterization of the Biocidal Properties of the AgImpregnated Fibers. Biotests using the Bacillus subtilis strain (3610 strain, wild type, personal gift by Maria Laaberki) were realized to evaluate the biocidal properties of the impregnated fibers. The cells were grown in an LB medium: $10 \mathrm{~g} / \mathrm{L}$ tryptone, $5 \mathrm{~g} / \mathrm{L}$ yeast extract, and $5 \mathrm{~g} / \mathrm{L} \mathrm{NaCl}$. A 3610 Bacillus subtilis culture grown overnight on liquid $\mathrm{LB}$ at $37^{\circ} \mathrm{C}$ was diluted to 

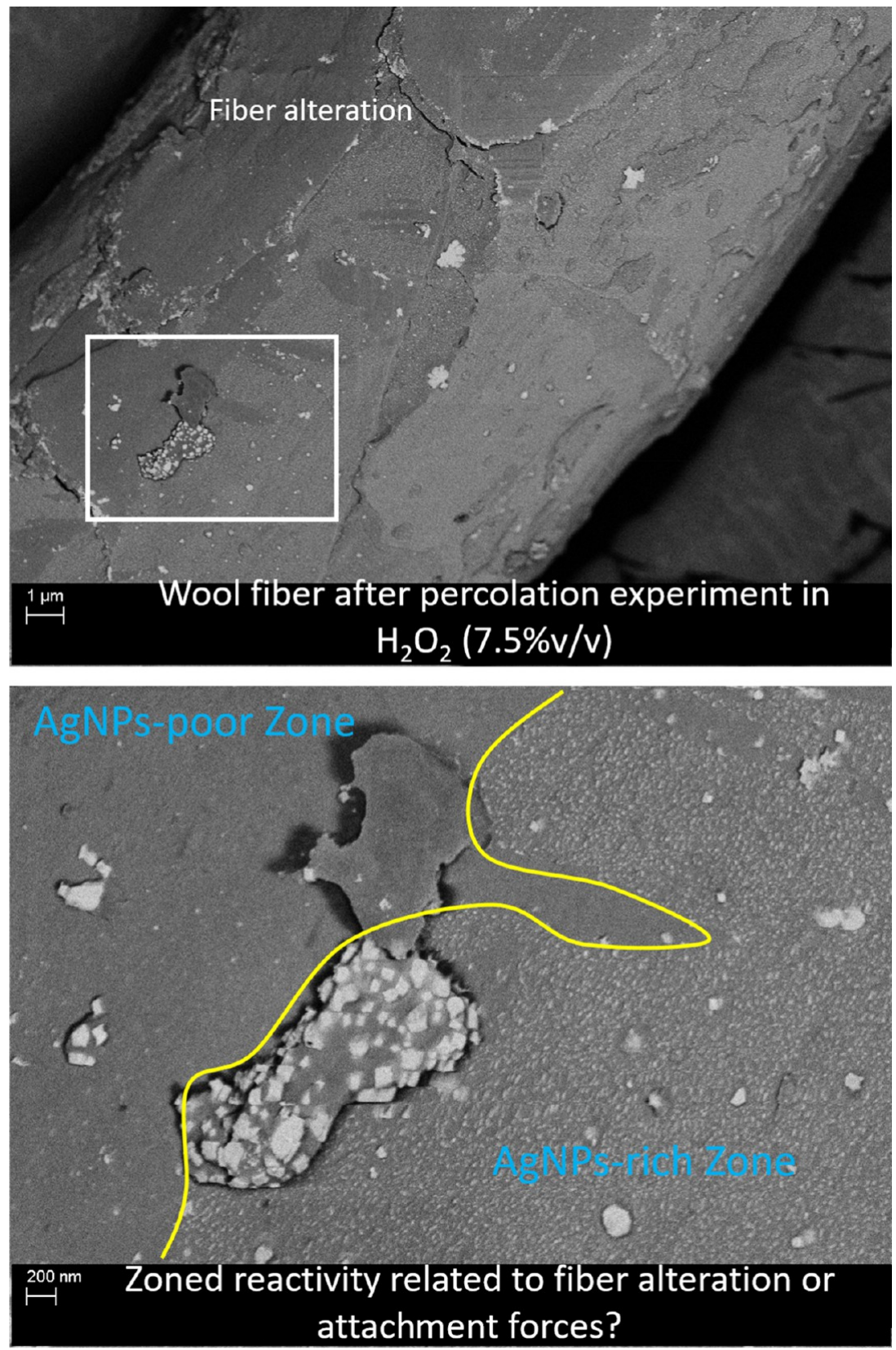

Figure 8. FESEM images at two different magnifications showing sheep's wool fiber after flow-through reactor experiment with oxygenated water $(7.5 \% \mathrm{v} / \mathrm{v})$. The high concentration of Ag-NPs remains still adhered onto fiber despite the surface fiber alteration.

$\mathrm{A} 600 \mathrm{~nm}=0.1 \mathrm{in} 10 \mathrm{~mL}$ of a fresh $\mathrm{LB}$ medium and incubated at $37^{\circ} \mathrm{C}$ and $200 \mathrm{rpm}$ until the A600nm reached the exponential phase ( 0.6). An amount of $300 \mu \mathrm{L}$ of this culture (or 108 cells) was applied uniformly on the surface of an LB agar plate $(22 \mathrm{~mL}$ of LB agar). Pellets of uniform size and weight $(5 \mathrm{~mm}, 11 \pm 1$ $\mathrm{mg}$ ) were pressed for each type of fiber impregnated with $\mathrm{Ag}$ (four replicates per type of fiber). The wool was not included in the test because the pellets lost their shape and the fibers unwound on the agar plate. Hydrophilic cotton was used as a negative control. Pellets were placed on the agar plate, and after 24,48 , and $72 \mathrm{~h}$ at $30^{\circ} \mathrm{C}$, the average diameter of the inhibition zone was measured. The biocide effect is evaluated by the diameter of the inhibition halos, normalized with respect to the diameter of the pellet size $(5 \mathrm{~mm})$. The significance of differences between treatments was assessed using a general linear model followed by a post hoc Tukey test using the software SPSS version 19.0.

FTIR Measurements. Five wool samples, wool without AgNPs (ref), wool-Ag-NPs washed with ultrapure water, and wool-Ag-NPs subjected to different oxidant solutions ( 0.05 and $0.5 \mathrm{M}$ of $\mathrm{HNO}_{3}$ and $7.5 \% \mathrm{v} / \mathrm{v}$ of $\mathrm{H}_{2} \mathrm{O}_{2}$ ), were characterized by FTIR. Herein, solid wool samples were analyzed using a Thermo Fisher IS50 Fourier transform infrared spectroscopy (FTIR) instrument, with a single-reflection diamond attenuated total reflection (ATR) crystal, located at ISTerre (Grenoble, France). ATR-FTIR spectra were collected using a resolution of $4 \mathrm{~cm}^{-1}$ and averaging 64 spectra in the wavenumber range of 4000-400 $\mathrm{cm}^{-1}$. 

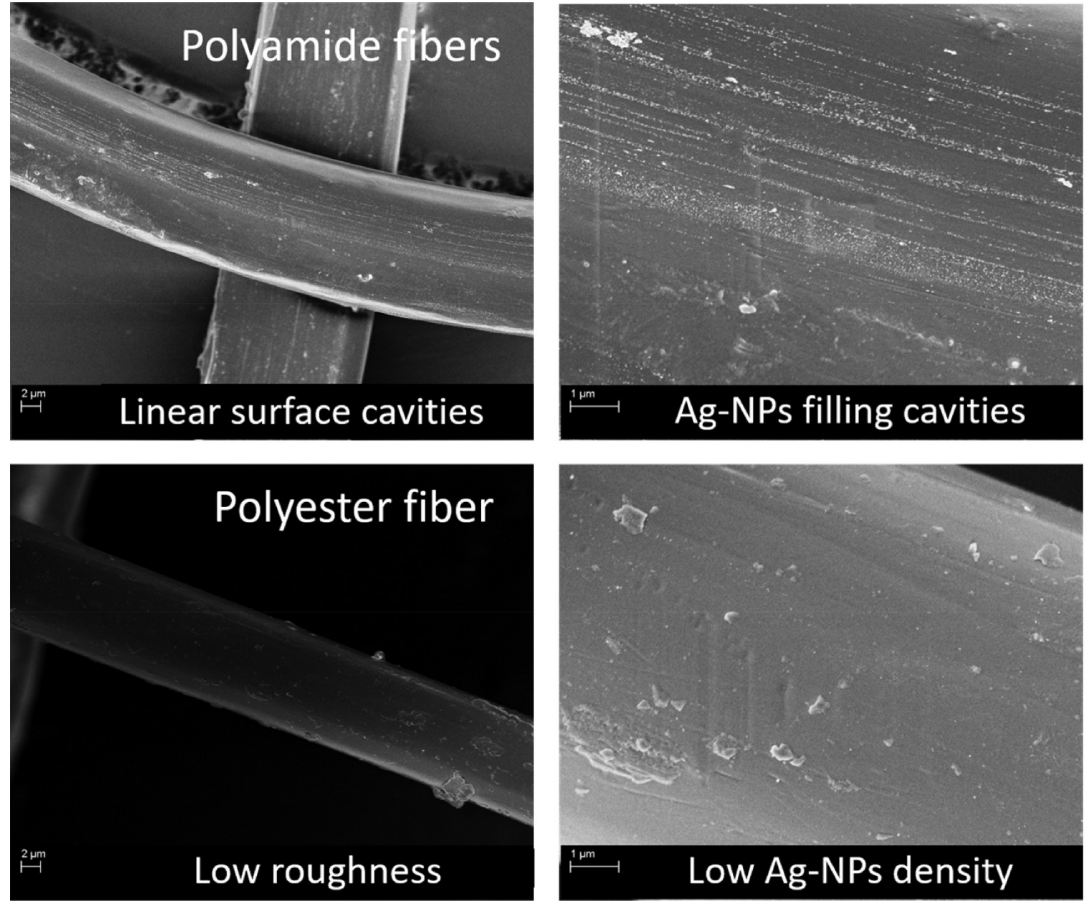
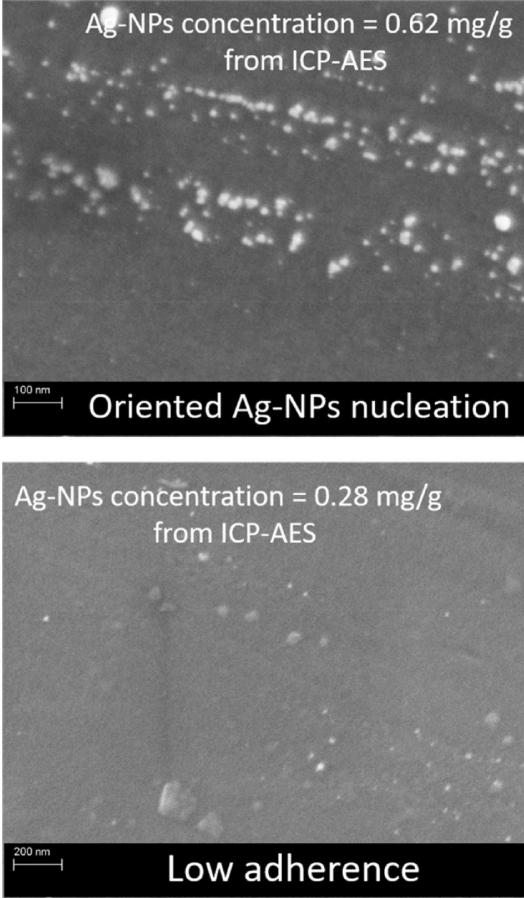

Figure 9. FESEM images at three different magnifications showing size, shape, aggregation degree, and 2D distribution of in situ formed Ag-NPs onto polyamide and polyester fibers. Ag-NPs concentration was also determined by ICP-AES in digested fibers containing Ag-NPs as explained in the Material and Methods section.

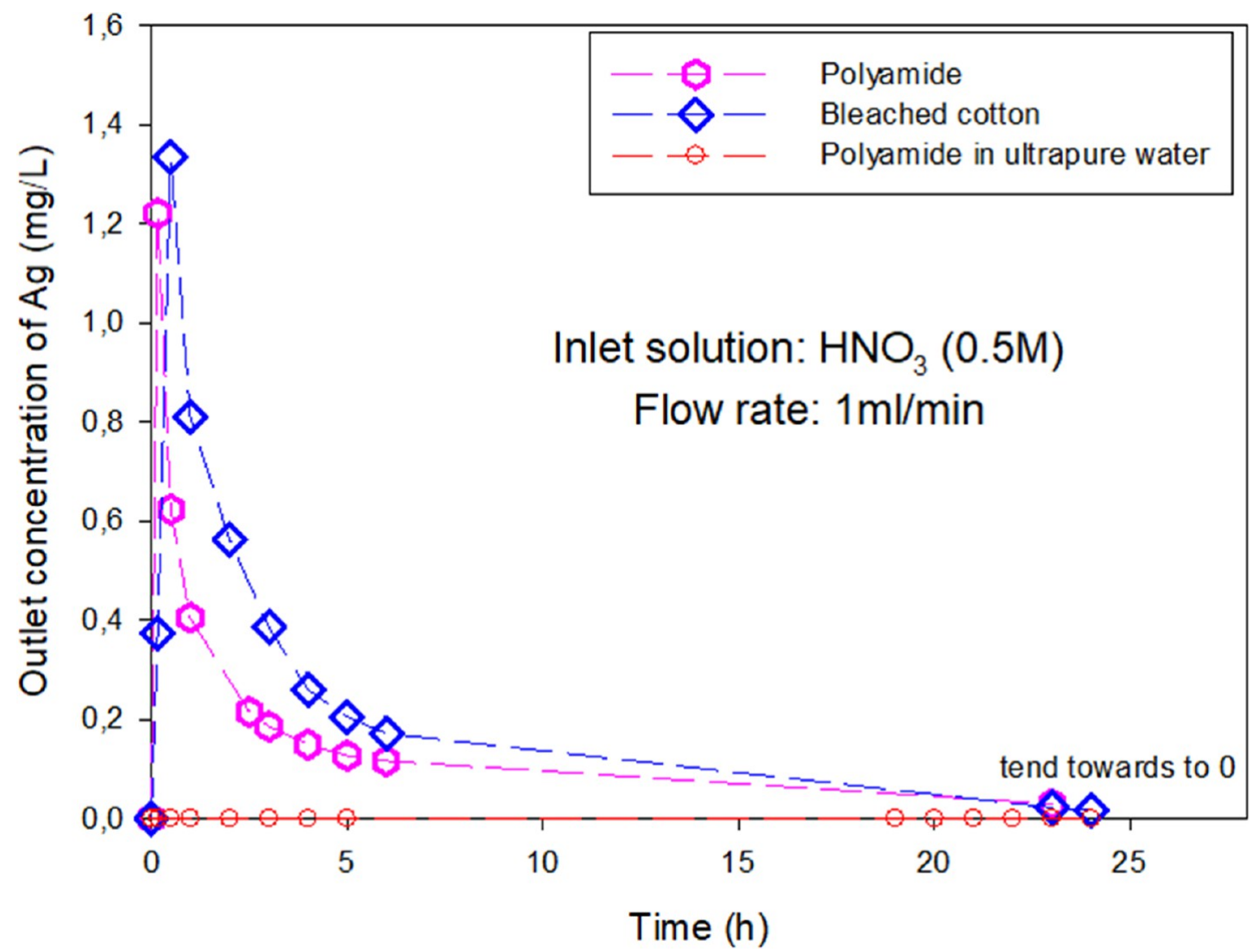

Figure 10. Breakthrough curves showing the oxidative release of $\mathrm{Ag}$ as a function of time obtained from flow-through reactor experiments. Comparison of reactivities between polyamide and bleached cotton in nitric acid. Inlet solutions: ultrapure water (control) in a polyamide system and nitric acid solutions $(0.5 \mathrm{M})$ in polyamide and bleached cotton; flow rate of $1 \mathrm{~mL} / \mathrm{min}$ and $\mathrm{Ag}$ outlet concentration measured by ICP-AES. 


\section{ASSOCIATED CONTENT}

\section{(1) Supporting Information}

The Supporting Information is available free of charge at https://pubs.acs.org/doi/10.1021/acsomega.0c04814.

(Figures S1-S3) Schematic synthesis method, photo of the flow-through reactor system for oxidative dissolution experiment of Ag-NPs, and ATR-FTIR spectra for five wool samples (PDF)

\section{AUTHOR INFORMATION}

\section{Corresponding Author}

German Montes-Hernandez - Univ. Grenoble Alpes, Univ. Savoie Mont Blanc, CNRS, IRD, IFSTTAR, ISTerre, 38000 Grenoble, France; 이이.org/0000-0002-8655-6530; Email: german.montes-hernandez@univ-grenoble-alpes.fr

\section{Authors \\ Mahaut Di Girolamo - Univ. Grenoble Alpes, Univ. Savoie Mont Blanc, CNRS, IRD, IFSTTAR, ISTerre, 38000 Grenoble, France \\ Géraldine Sarret - Univ. Grenoble Alpes, Univ. Savoie Mont Blanc, CNRS, IRD, IFSTTAR, ISTerre, 38000 Grenoble, France; 10 orcid.org/0000-0002-1709-3456 \\ Sarah Bureau - Univ. Grenoble Alpes, Univ. Savoie Mont Blanc, CNRS, IRD, IFSTTAR, ISTerre, 38000 Grenoble, France \\ Alejandro Fernandez-Martinez - Univ. Grenoble Alpes, Univ. Savoie Mont Blanc, CNRS, IRD, IFSTTAR, ISTerre, 38000 Grenoble, France \\ Cécile Lelong - BIG, LCBM, ProMD, UMR CNRS-CEA- UGA, 38054 Grenoble, France \\ Elise Eymard Vernain - BIG, LCBM, ProMD, UMR CNRS- CEA-UGA, 38054 Grenoble, France}

Complete contact information is available at:

https://pubs.acs.org/10.1021/acsomega.0c04814

\section{Notes}

The authors declare no competing financial interest.

\section{ACKNOWLEDGMENTS}

The authors are grateful to CNRS and UGA for providing funding support. The Labex SERENADE (ANR-11-LABX0064) project funded the master (M1R) of M.D.G. at ISTerre. We thank Christine Lancelon Pin from CERMAV (Grenoble, France) for the preparation of the thin sections. Electron microscopy was performed at the CMTC characterization platform of Grenoble INP supported by the Centre of Excellence of Multifunctional Architectured Materials "CEMAM" (no. AN-10-LABX-44-01) funded by the "Investments for the Future" program. The ATR-FTIR instrument was funded by Region Auvergne Rhone-Alpes CPER funds awarded to the project "CEMBRO". We thank the staff of the Geochemistry and Mineralogy platform at ISTerre for their technical support. ISTerre is a part of Labex OSUG@2020 (ANR10 LABX56).

\section{REFERENCES}

(1) Yetisen, A. K.; Qu, H.; Manbachi, A.; Butt, H.; Dokmeci, M. R.; Hinestroza, J. P.; Skorobogatiy, M.; Khademhosseini, A.; Yun, S. H. Nanotechnology in Textiles. ACS Nano 2016, 10, 3042-3068.

(2) Nakamura, S.; Sato, M.; Sato, Y.; Ando, N.; Takayama, T.; Fujita, M.; Ishihara, M. Synthesis and Application of Silver Nanoparticles (Ag
NPs) for the Prevention of Infection in Healthcare Workers. Int. J. Mol. Sci. 2019, 20, 3620.

(3) Akter, M.; Sikder, T. M.; Rahman, M. M.; Ullah, A. K. M. A.; Hossain, K. F. B.; Banik, S.; Hosokawa, T.; Saito, T.; Kurasaki, M. A systematic review on silver nanoparticles-induced cytotoxicity: Physicochemical properties and perspectives. J. Adv. Res. 2018, 9, 1-16.

(4) Mitrano, D. M.; Motellier, S.; Clavaguera, S.; Nowack, B. Review of nanomaterial aging and transformations through the life cycle of nano-enhanced products. Environ. Int. 2015, 77, 132-147.

(5) Stefaniak, A. B.; Duling, M. G.; Lawrence, R. B.; Thomas, T. A.; LeBouf, R. F.; Wade, E. E.; Virji, M. A. Dermal exposure potential from textiles that contain silver nanoparticles. Int. J. Occup. Environ. Health 2014, 20, 220-234.

(6) Wagener, S.; Dommershausen, N.; Jungnickel, H.; Laux, P.; Mitrano, D.; Nowack, B.; Schneider, G.; Luch, A. Textile Functionalization and Its Effects on the Release of Silver Nanoparticles into Artificial Sweat. Environ. Sci. Technol. 2016, 50, 5927-5934.

(7) Pradas del Real, A. E.; et al. Fate of Ag-NPs in Sewage Sludge after Application on Agricultural Soils. Environ. Sci. Technol. 2016, 50, 17591768.

(8) Bacciarelli-Ulacha, A.; Rybicki, E.; Matyjas-Zgondek, E.; Pawlaczyk, A.; Szynkowska, M. I. A New Method of Finishing of Cotton Fabric by in Situ Synthesis of Silver Nanoparticles. Ind. Eng. Chem. Res. 2014, 53, 4147-4155.

(9) Abbasi, A. R.; Morsali, A. Synthesis and properties of silk yarn containing $\mathrm{Ag}$ nanoparticles under ultrasound irradiation. Ultrason. Sonochem. 2011, 18, 282-287.

(10) Mahmud, S.; Pervez, M. N.; Sultana, M. Z.; Habib, M. A.; Liu, H.H. Wool Functionalization by Using Green Synthesized Silver Nanoparticles. Orient. J. Chem. 2017, 33, 2198-2208.

(11) Kang, C.; Kim, S. S.; Ahn, D.; Kim, S. J.; Lee, J. Effective surface attachment of $\mathrm{Ag}$ nanoparticles on fibers using glycidyltrimethylammonium chloride and improvement of antimicrobial properties. RSC Adv. 2017, 7, 23407-23414.

(12) Yazdanshenas, M. E.; Shateri-Khalilabad, M. The Effect of Alkali Pre-treatment on Formation and Adsorption of Silver Nanoparticles on Cotton Surface. Fibers Polym. 2012, 13, 1170-1178.

(13) Feng, J.; et al. Scalable and Environmentally Benign Process for Smart Textile Nanofinishing. ACS Appl. Mater. Interfaces 2016, 8, 14756-14765.

(14) Hontañón, E.; Meyer, J.; Blanes, M.; Cambra, V.; Guo, X.; Masuhr, M.; Muntean, A.; Santos, L.; Nirschl, H.; Kruis, E. A Sustainable Route for Antibacterial Nanofinishing of Textiles. Int. J. Theor. Appl. Nanotechnol. 2016, 4, 17-27.

(15) Mura, S.; Greppi, G.; Malfatti, L.; Lasio, B.; Sanna, V.; Mura, M. E.; Marceddu, S.; Lugliè, A. Multifunctionalization of wool fabrics through nanoparticles: A chemical route towards smart textiles. J. Colloid Interface Sci. 2015, 456, 85-92.

(16) Ilić, V.; Šaponjić, Z.; Vodnik, V.; Potkonjak, B.; Jovančić, P.; Nedeljković, J.; Radetić, M. The influence of silver content on antimicrobial activity and color of cotton fabrics functionalized with $\mathrm{Ag}$ nanoparticles. Carbohydr. Polym. 2009, 78, 564-569.

(17) Lombi, E.; Donner, E.; Scheckel, K. G.; Sekine, R.; Lorenz, C.; Goetz, N. V.; Nowack, B. Silver speciation and release in commercial antimicrobial textiles as influenced by washing. Chemosphere 2014, 111, $352-358$.

(18) Lorenz, C.; Windler, L.; von Goetz, N.; Lehmann, R. P.; Schuppler, M.; Hungerbühler, K.; Heuberger, M.; Nowack, B. Characterization of silver release from commercially available functional (nano)textiles. Chemosphere 2012, 89, 817-824.

(19) Spielman-Sun, E.; Zaikova, T.; Dankovich, T.; Yun, J.; Ryan, M.; Hutchison, J. E.; Lowry, G. V. Effect of silver concentration and chemical transformations on release and antibacterial efficacy in silvercontaining textiles. NanoImpact 2018, 11, 51-57.

(20) Ding, D.; Chen, L.; Dong, S.; Cai, H.; Chen, J.; Jiang, C.; Cai, T. Natural ageing process accelerates the release of $\mathrm{Ag}$ from functional textile in various exposure scenarios. Sci. Rep. 2016, 6, 37314. 
(21) Mitrano, D. M.; Limpiteeprakan, P.; Babel, S.; Nowack, B. Durability of nano-enhanced textiles through the life cycle: releases from landfilling after washing. Environ. Sci.: Nano 2016, 3, 375-387.

(22) Mitrano, D. M.; Rimmele, E.; Wichser, A.; Erni, R.; Height, M.; Nowack, B. Presence of Nanoparticles in Wash Water from Conventional Silver and Nano-silver Textiles. ACS Nano 2014, 8, 7208-7219.

(23) Xu, L.; Wang, Y. Y.; Huang, J.; Chen, C. Y.; Wang, Z. X.; Xie, H. Silver Nanoparticles: Synthesis, medical applications and biosafety. Theranostics 2020, 10, 8996-9031.

(24) Zhang, Z.; Shen, W.; Xue, J.; Liu, Y.; Liu, Y.; Yan, P.; Liu, J.; Tang, $\mathrm{J}$. Recent advances in synthetic methods and applications of silver nanostructures. Nanoscale Res. Lett. 2018, 54.

(25) Hsueh, Y.-H.; Lin, K.-S.; Ke, W.-J.; Hsieh, C.-T.; Chiang, C.-L.; Tzou, D.-Y.; Liu, S.-T. The Antimicrobial Properties of Silver Nanoparticles in Bacillus subtilis Are Mediated by Released Ag+ Ions. PLoS One 2015, 10, No. e0144306.

(26) Tripathi, D. K.; Tripathi, A.; Shweta; Singh, S.; Singh, Y.; Vishwakarma, K.; Yadav, G.; Sharma, S.; Singh, V. K.; Mishra, R. K.; Upadhyay, R. G.; Dubey, N. K.; Lee, Y.; Chauhan, D. K. Uptake, Accumulation and Toxicity of Silver Nanoparticle in Autotrophic Plants, and Heterotrophic Microbes: A Concentric Review. Front. Microbiol. 2017, 8.

(27) Panayiotou, H. Vibrational Spectroscopy of Keratin Fibres : A Forensic Approach. $\mathrm{PhD}$ thesis of Queensland University of Technology, Australia, 2004.

(28) Ramakrishnan, N.; Sharma, S.; Gupta, A.; Alashwal, B. Y. Keratin Based Bioplastic Film from Chicken Feathers and Its Characterization. Int. J. Biol. Macromol. 2018, 111, 352-358.

(29) Patil, N. V.; Netravali, A. N. Enhancing Strength of Wool Fiber Using a Soy Flour Sugar-Based "Green" Cross-Linker. ACS Omega 2019, 4, 5392-5401.

(30) Vasconcelos, A.; Freddi, G.; Cavaco-Paulo, A. Biodegradable Materials Based on Silk Fibroin and Keratin. Biomacromolecules 2008, 9, 1299-1305.

(31) Zhang, Q.; Wu, D.; Qi, S.; Wu, Z.; Yang, Y.; Jin, R. Preparation of ultra-fine polyimide fibers containing silver nanoparticles via in situ technique. Mater. Lett. 2007, 61, 4027-4030.

(32) Xu, X.; Yang, Q.; Wang, Y.; Yu, H.; Chen, X.; Jing, X. Biodegradable electrospun poly(L-lactide) fibers containing antibacterial silver nanoparticles. Eur. Polym. J. 2006, 42, 2081-2087.

(33) Hu, Q.; Wu, H.; Zhang, L.; Fong, H.; Tian, M. Rubber composite fibers containing silver nanoparticles prepared by electrospinning and in-situ chemical crosslinking. eXPRESS Polymer Lett. 2012, 6, 258-265. (34) Lee, H. K.; Jeong, E. H.; Baek, C. K.; Youk, J. H. One-step preparation of ultrafine poly(acrylonitrile) fibers containing silver nanoparticles. Mater. Lett. 2005, 59, 2977-2980. 